\title{
Employee/Management Sabotage Effects on Organizational Output
}

\author{
Etebong Attah Umana ${ }^{1} \&$ L. C. Okafor ${ }^{1}$ \\ ${ }^{1}$ Department of Business Management, Faculty of Management Sciences, Ebonyi State University, Abakaliki, \\ Nigeria \\ Correspondence: Etebong Attah Umana, Department of Business Management, Faculty of Management Sciences, \\ Ebonyi State University, Abakaliki, Nigeria.
}

Received: March 11, 2019

Accepted: April 30, 2019

Online Published: May 12, 2019

doi:10.5430/jms.v10n3p37

URL: https://doi.org/10.5430/jms.v10n3p37

\begin{abstract}
This study examines how employee sabotage affects organizational output in First Bank Plc, Calabar. The purpose was to identify the causes of employee sabotage, to examine how employee sabotage destroys the image and reputation of the organization, to examine how employee insubordination thwart the achievement of team work accomplishment and organizational effectiveness, to examine how employee refusal to produce product/service affect organizational output and to determine how employee sabotage reduce the security strength of the organization. The study employed survey design and used questionnaire to gather data from sampled respondents. Data was analyzed using simple percentage method. Based on the findings, it was revealed that sabotage at workplace by employee can damage the property, image and reputation of an organization. It was also revealed that employee insubordination thwart the achievement of team work accomplishment and organizational effectiveness. It was equally shown that employee sabotage reduces the security strength of the organization, thus expose the organization to competitive thread and that sabotage by employee leads to waste of resources in the organization, thus low organizational output. It was thus recommended that organizations should do a thorough background checks to know the type of employee that has been hired. Also, organizations should reinforce codes of conduct which will add weight to disciplinary response (court claim) to regulate employees' behaviours if the employee abuses the rules.
\end{abstract}

Keywords: employee sabotage, employee retaliation, passive sabotage, active sabotage, workplace sabotage, couterproductive workers' behavior

\section{Introduction}

Considering recent reports of organizations losing lots of money as years goes by due to the issue of employee and management sabotage, it is crucial the reasons and sources of such counterproductive behavior should be understood (Flaherty and Moss 2017). Sabotage is defined as a behaviour intended to damage, disrupt, or subvert the organization's operations for the personal purposes of the saboteur by creating unfavorable publicity, embarrassment, delays in production, damage to property, the destruction of working relationships, or the harming of employees or customers (Crino, 2014). Sabotage is, therefore, a dangerous behavior that has both professional and legal implications for both the saboteur and the organization. Engaging in sabotage can lead to employee termination, lawsuits, and capital loss (Flaherty and Moss 2017).

There have been a lot of theories explored by researchers to analyze possible previous circumstances to sabotage behavior. However, sabotage is seen as a complex counterproductive work behavior that consists of at least two categories of behavior; restoration equity and retaliation. Sabotage researchers (Fisher and Baron, 2012) have been primarily interested in restoration equity (Adams, 2015), which describes a situation where individuals observe an inequality between the level of their contributions and rewards. These individuals then participate in thoughts or behaviors to restore this balance. Research with restoration equity has developed the theory and other findings of distributive justice. Distributive justice is a form of organizational justice that deals with concerns of the observed fairness of resource distribution and outcome resolution (Cropanzano and Ambrose, 2011). The use of distributive justice to elucidate restoration equity has received the most consideration by sabotage researchers (Cropanzano and Greenberg, 2017).

Sabotage has another form, employee retaliation, which has not been as thoroughly studied as restoration equity. Employee retaliation is activities intended to punish, disrupt, or seek revenge against one's employer, co-worker, or 
boss (Skarlicki and Folger, 2017). Many writings on employee retaliation has started to use organizational justice theories to better comprehend sabotage behavior but these investigations of employee retaliation have relied on self-report methodology to measure retaliation behavior. Reporting this type of negative behavior can result in serious penalties for employees and elevates the question of the exactitude in self-report methodology. This accuracy issue deals with the preparedness of participants to be honest and report instead of getting involved in sabotage behavior.

Employee sabotage is a counterproductive behavior in organizations which has received little literature attention, because of the severity of this negative behavior and the difficulty of measurement. Thus, it is imperative to make progress in the research on employee retaliation to better understand why individuals engage in these and other related types of counterproductive work behaviors. The purpose of this study was to examine how employee /management sabotage affect organizational output.

\subsection{Statement of the Problem}

In an organizational setting, employee sabotage can be seen in different ways. Employee can stop production process or hinder services rendered to customers. This can be done through stopping of certain activities like production and hampering the supply of raw materials or component parts, an indefinite strike of a facility, a partial strike at regular or irregular intervals, and seizure of the finished product inventory to prevent delivery to customers.

Also, employees can thwart the activities of the organization. Such employees are people who reject policies and norms in manners that can harm the organizations in which they work. They may also resort to the misuse of office resources, lie to colleagues, participate in blackmail or distribute sensitive, confidential data without authorization. They may also pull malicious mischiefs or communicate offensively to stir outrage deliberately.

Also, employee can display counter-normative behaviours in the workplace which leads to workplace deviance and this can thwart an organization's well-being. Though deviants may constitute a minority, their impact on productivity, performance, staff morale and workplace culture can be enormous. Deviant behaviours, or behaviours instigated by employees that infringe organizational norms, can collectively cost organizations billions of naira per year. Although the cost of sabotage is difficult to determine, it is believed to be on the increase. With very little major research work written, it is an area whose investigation is challenging for a variety of reasons. Since sabotage is often implemented via anti-social means (violence and destructiveness), a primary problem in the investigation of sabotage is an association with criminal activity. Investigating sabotage, therefore, may bring legal authorities into the research picture.

Moreso, sabotage is an activity which, because of legal consequences, employees prefer not to discuss with outsiders, or insiders. Reporting information to researchers regarding sabotage may mean the job of a coworker or one's own job. Therefore, it can be expected that many people who are involved in sabotage or mindful of it would decline to reveal important qualitative or quantitative information. Lastly, since sabotage seems not to be a daily occurrence by particular groups or individuals, it is difficult to evaluate the degree to which any saboteur is responsible for a set of sabotage behaviors. Despite these difficulties, some advances toward understanding sabotage can be made if these problems are challenged directly.

\subsection{Objectives of the Study}

The primary objective of the study is to examine how employee sabotage affects organizational output. The specific objectives include:

i) To examine how employee damage of organization property destroys the image and reputation of the organization

ii) To examine how employee insubordination thwart the achievement of team work accomplishment and organizational effectiveness

iii) To examine how employee refusal to produce product/service affect organizational output

iv) To determine how employee sabotage reduce the security strength of the organization

\section{Theoretical Framework}

The theory that fit the study is Social action theory. This theory was propounded by Max Weber in 1937. The theory of social action assumes that humans fluctuates their actions according to social contexts and how it will affect other people; when a prospective reaction is not appropriate, the action is modified accordingly. Action can mean either a basic action or an advanced social action, which not only has a meaning but is focused at other actors and causes action. 
In social action theory, Weber believes that bureaucratic organizations are the principal institutions in society. Weber believes that bureaucracies (institutions) consist of individuals carrying out rational social actions calculated to achieve the goals of bureaucracies. Weber views the whole progress of modern societies in terms of a move towards rational social action. Thus, modern societies are undergoing the process of rationalization.

According to Weber, all human actions are directed by meanings. He acknowledged numerous types of action that are distinguished by the meanings on which they are based: Affective or emotional action - this stems from an individual's emotional state at a particular time. Traditional action - this is based on established custom; people act in a certain way because of built-in habits: they have always done things that way. Rational action - involves a clear awareness of a goal. The relevance of the theory to the study is that it stresses on reasons particular individual employees and groups are defined as 'deviant' where deviance can be defined as "behaviour that does not follow the standards of a particular social group.

\subsection{Concept of Employee Sabotage}

Employee sabotage is a purposeful action by workers targeted at weakening a polity, effort or organization through subversion, obstruction, disruption or destruction. It is also any behavior by a payroll employee which is planned to cause a production or profit loss for the targeted organization (Adams, 2015). Sabotage is one of the many diverse forms of counterproductive work behaviors in organizations. The literature on sabotage comprises primarily of two types of sabotage behavior; restoration equity and retaliation behavior. Restoration equity consists of behaviors that attempt to restore or counterbalance a perceive loss in one's situation (e.g. vandalizing or stealing company supplies when denied a pay raise). Employee retaliation behaviors are those behaviors that are intended to punish, disrupt, or seek revenge against one's employer, coworker, or boss (Skarlicki and Folger, 2017). Purposefully damaging equipment, intentionally working slow, taking long breaks are examples of employee retaliation behavior.

Sabotage researchers have developed research using models of possible antecedents and explanations for occurrence of this type of behavior. Proposed influences on sabotage behavior have included: aggression, workplace frustration, emotions, individual and personality factors and the organizational context (Greenberg, 2010; Skarlicki and Folger 2017). Similar to other research with counterproductive work behaviors, sabotage researchers have investigated different ways to predict sabotage.

Employee sabotage occurs in many settings including political campaigns, wars, sports tournaments, and organizations. Given the variety of definitions of sabotage that exists in different contexts. Lazear (2017) define employee sabotage as any (costly) actions that one worker takes that adversely affect the output of another. In business organizations, sabotage can be targeted at other employees (horizontal sabotage) or at management or the organization (vertical sabotage). Although both types of sabotage are observed in practice.

Organizations typically consider sabotage activities to be highly undesirable and would punish saboteurs if they were discovered (Analoui, 2015). Therefore, these activities are often undertaken surreptitiously and concealed carefully. It is exceptionally difficult for researchers to collect reliable data concerning sabotage in actual organizational settings.

A large stream of analytical and experimental literature has surveyed sabotage behavior in various types of tournaments (Amegashie, 2013). Tournaments, which are commonly used in organizations, refer to incentive systems where individuals (or teams) compete for a limited number of rewards such as bonus and promotion opportunities (Berger, 2013). Tournament incentives are essentially contracts linking employees' compensation to their relative performance (that is, their performance relative to other employees). Literature has documented both positive and negative effects of tournament incentives on employee's performance (Hannan, 2011). Employees under a tournament incentive can be motivated to exert effort to advance their absolute performance (positive effect), and/ or reduce their competitors' performance by sabotaging them (negative effect) (Chen, 1987).

Existing theoretical models and experimental studies of sabotage in tournaments, proposed and conducted by economists, center on the economic reasons for sabotage; that is, sabotage can bring economic benefit to saboteurs by increasing their chance of receiving an advantageous outcome. The size of the benefit (cost) of sabotage is positively (negatively) correlated with the level of sabotage behavior. The greater the benefit, the more sabotage behavior is observed. For example, in a repeated tournament setting with three persons competing for a bonus (that is, the difference in pay between one winner and two losers), a larger bonus (that is greater benefit of sabotage) leads to more sabotage effort (Harbring and Irlenbusch, 2011). However, if the benefit of sabotage is sufficiently small, sabotage behavior may even disappear. In a lobbying tournament setting used by Konrad (2010) where multiple lobbying groups compete for a prize (that is, a favorable policy outcome), sabotage effort directed toward a lobbying group reduces that 
group's chance of winning, thereby increasing all other groups' chances of winning. This means that the benefit of sabotage is similar to a public good, shared by all other groups.

\subsection{Types of Employee Sabotage}

Employee sabotage can be classified into two categories: passive sabotage and active sabotage. According to Decision Wise research, $4 \%$ of a typical work force are active saboteurs, and $28 \%$ are passive saboteurs (Colbert, A; Mount, M; Witt, L; Harter, J and Barrick, M 2004). Passive sabotage is actions that should have been taken by the workers that were not taken and the inaction leads to a negative effect on the output of another worker. As an example, passive saboteurs may keep away important information from their colleagues or refuse to share knowledge with others which would help to improve outcomes. In contrast, active sabotage refers to actions taken by a worker which should not have been taken, and these actions are harmful to the output of another worker. As an example, an active saboteur may actively gossip about a co-worker, steal or hide a co- worker's tools or destroy a co-worker's work output (Robinson and Bennett, 2015).

Passive sabotage has been examined by psychologists studying organizational citizenship and by management accounting researchers in settings where passive sabotage takes the form of a lack of cooperation including refusal to help or share information (Berger, 2013). In contrast, active sabotage has been look at much less often in these two streams of literatures. It is important to investigate active sabotage although it is rarer in practice than passive sabotage because active sabotage sometimes causes more severe impact to co-workers or organizations. The focus of this study is active sabotage behavior. Sabotaging coworkers, although not directly targeted at the organization per se, can weaken the value of a firm by decreasing the productivity of co-workers. If sabotaging each other becomes part of the organization's culture, good workers may leave, incurring a talent loss to the organization.

The types of employee sabotage cost are not limited to just monetary costs (such as time, money, effort, etc.). Psychology literature has shown that individuals have a preference for conformity with social norms of honesty and fairness (Colquitt, 2011). When sabotage activities are perceived by a saboteur as a violation of social norms, the saboteur may feel guilty or have a negative self-image after sabotaging others. Such unfavorable feelings or other psychological effects experienced or anticipated by a saboteur as a form of psychological cost may stop a potential saboteur from sabotaging in the first place. Therefore, one potential way to reduce sabotage is to increase the psychological cost of sabotage. For example, sabotage behavior can be alleviated by using language that clearly labels destructive activities as sabotage (Harbring and Irlenbusch, 2011). Labeling destructive activities with the negative term "sabotage" increases the psychological costs associated with these activities as the term "sabotage" highlights that the activity is undesirable and violates societal norms. Another form of sabotage cost comes from revenge or retaliation from victimized individuals. When a saboteur's identity is revealed, the likelihood of retaliation and the cost of sabotage increases, therefore sabotage effort is increased (Harbring, 2014).

\subsection{Causes of Sabotage in an Organization}

Konrad (2010) asserted that the causes of sabotage among employees in the organization are:

i) Group identity: An individual's sense of belonging and affiliation towards a group is an indicator of the individual's group identity. Strong group identity can develop the psychological closeness between self and others in the group, conceptualized as self- other overlap. Individuals with greater group identity are also more likely to see themselves as similar to others in their group. Higher perceived similarity increases social comparison, because people compare themselves more with others who are more similar to themselves and considered as a good gauge of their own ability. Increased social comparison leads to more competition where people strive to do better than others (Garcia, 2013). Therefore, strengthening group identity may increase competition and therefore sabotage behavior of employees. However, there is a counter argument that individuals with greater self-other overlap are more likely to feel the outcomes of other group members as their own, and therefore they are also more likely to protect others' outcomes by not sabotaging others, except where groupthink exist, where minority opinions are stifled (Umana and Okafor, 2019). Charness (2014) supports this counter argument that people sabotage group members to a lesser extent if the group members are from the same school than if they are from a different school. He speculated that group identity is the reason for the reduced sabotage.

ii) Compensation: Empirical evidence supports that individuals may sabotage their coworkers to achieve a better performance rank than others. Sabotage is driven by the following three mechanisms.

Many people often appraise themselves by comparing "self" with others on certain dimensions. A favorable evaluation can enhance self-esteem, especially if the evaluation such as income, ability, and academic performance is important and relevant to one's self-esteem. One's income level can be a relevant comparison dimension because it represents 
social status. Chen (1987) used survey data to validate that people are concerned about their income relative to others' income (that is, relative income). He found that half of surveyed respondents preferred to earn more money than others (that is, better relative income status), even though this better relative income status was obtained at the cost of half of their absolute income.

Berger (2013) showed that income comparison within a community affects community members' assessments of life satisfaction. Experimental research demonstrates that people who have anti-social preferences may reduce another's income to increase their own relative income. Social comparison on the income dimension may occur under the PR contract where people receive varying levels of income proportional to their individual performance. The performance-based ranking they receive is essentially their income ranking. In contrast, social comparison on the income dimension cannot occur when people earn the same level of income, that is, the flat wage. In other words, the PR contract provides an additional comparison dimension (income) that may be personally relevant to one's self-esteem. Therefore, the intensity of social comparison will be stronger under the PR contract.

Also, victims of sabotage may experience negative feelings such as anger, and may feel disadvantaged in their rank status. They may sabotage others too as a way to vent their negative feelings and/or to narrow the disadvantageous rank position. For example,

Colbert et al (2004) finds that people have the tendency to behave aggressively toward others to improve their mood. Harbring and Irlenbusch (2011) show that people hold strong norms about fair allocation of resources and will do whatever it takes to correct perceived inequity. People working under a PR contract will experience greater negative feelings, have greater motivation to vent such negative feelings, and are therefore more likely to sabotage others. Also, people working under a PR contract feel greater disadvantage in relative rank and earnings, and have greater motivation to reduce the disadvantageous relative rank and earnings by sabotaging others.

\subsection{Organizational Output}

Organizational output is the outcome which the organization planned to achieve. It is also an outcome which becomes the performance area that the organization has decided to maximize (Hannan, 2011). Organizational output can be classified according to Analoni (2015) in the following ways:

i) Strategic leadership and planning: This is to develop exceptional organizational leaders (executive and Board) who stays focused on the core mission, maintain management practices that promote quality, drive program effectiveness, hold staff and managers accountable for results, and ensure financial health and sustainability.

ii) Outcomes-focused management: This is to support organizations to develop and sustain clear performance standards, and agreed-upon outcome measurements, that they monitor and use to understand and improve staff performance. Sufficient depths are developed so that managers have the appropriate scope and scale of authority to ensure that front line staff delivers services at high levels of performance.

iii) Performance management: This is to support organizations to monitor and utilize data in managing their performance for continuous improvement purposes, so that they can drive towards better outcomes for the customers and other stakeholders they serve. This means developing systems for both day-to-day and strategic data interpretation and use.

iv) Program quality and effectiveness: This is to ensure that each organization has a strategic, structured programming approach, a culture that values learning, clear implementation and performance standards, systematic methods to measure implementation and performance standards, a responsive approach to progress monitoring, and can be relied on to deliver services at high levels of quality and fidelity.

\subsection{How Employee Sabotage Affects Organizational Output}

Organizations that have experienced employee sabotage tries not to discuss it, fearing copycat actions or bad publicity. Managers talk about it in hushed voices and try to explain it away with reasons that are less frightening especially to their shareholders. But it is real and very dangerous. Employee saboteurs inflict damage to the property, reputation, product or service of an organization. Their work can take different forms: equipment destruction, computer viruses, poisoning, working slowly, stealing or purposely treating a customer rudely. The reasons for employee sabotage can be frustration, a need to feel mastery over the environment or an opportunity to settle a difference with a manager or co-worker. Because it can be rewarding to the saboteur (if left unpunished), it is likely repeated. In an organization, workers can succeed in shutting down the plant on purpose on a sunny afternoon (to get an early start on the weekend), start a fire, break equipment, produce damaged goods, and work slowly just to sabotage the organization. Resources can be wasted on rectifying the wrong problem (Robinson and Bennett, 2015). 
Employee sabotage is a central determining factor of the balance of power in contemporary organizations. Throughout the history of industry and commerce, it has been used as a weapon by those with less formal power and has been practiced and refined as an art of resistance against management. It has been discussed widely, but has been the subject of only a few comprehensive and sustained studies. Loose definitions of the concept predominate. It is defined here as deliberate action or inaction that is intended to damage, destroy or disrupt some aspect of the workplace environment, including the property, product, processes or reputation of the organization (Lazear, 2017). In contrast to the image of the 'mad saboteur', careful review of existing research leads to the conclusion that most acts of sabotage are highly symbolic, are restrained and selective, are the product of collective or even conspiratorial efforts, and are performed with technical sophistication. They tend to be deliberate and premeditated rather than impulsive and careless. Some level of workplace sabotage corresponds to the class-based organization of society and its associated distribution of advantages and disadvantages. This is compounded in effect due to issues of gender, race and ethnicity and other social barriers that exist. However, these macro conditions for sabotage do not fully explain its occurrence (Crino, 2014).

\subsection{Ways of Handling Employee Sabotage in an Organization}

Fisher and Baron (2012) posit that the best ways of handling employee sabotage include:

i) Start with a risk assessment: What kind of breaches would bring down your firm, and who would benefit most? Think about what is at greatest risk. Maybe its confidential data, or expensive stock stored vulnerably. Who has access but may not be trustworthy? Based on the answers, create a plan to ward off unwelcome actions.

ii) Conduct employee background checks: For every potential hire perform a background check. It can reveal a criminal record, suspicious references, and lies on resumes. Doing a credit probe (with permission) could show poor financial management. Better to know these things up front than to discover you've hired a convicted embezzler.

iii) Reinforce codes of conduct: No matter how small the company, there should be a code of conduct in place. At a minimum it will add weight to your disciplinary response (or court claim) if an employee abuses the rules. At best it inhibits bad behaviours by pointing out what's expected, and the consequences of breaching procedures. Include sections on ethical activities, confidentiality and whistleblowing.

iv) Keep private conversations private: Sometimes staff will go to coffee shops or other public venues to talk business. Make sure they know that loose lips can sink ships. Speaking loudly on mobile phones in public poses the same risk. You never know who's nearby. Employees are particularly exposed if their clothing or accessories show the name of the company. In addition, blurting out secrets on non-secured instant messaging or email apps is asking for trouble.

v) Improve the security of premises: Whether situated in a small building, a store or your home, small businesses need to watch for intrusions. Install an adequate security system. That likely includes video cameras in strategic locations. Also an alarm monitoring system and locks on private file cabinets. Don't forget the basics either, such as not leaving important documents lying around.

vi) Increase virtual protections: Cyber-security is a huge issue. One unblocked hack could expose your company's hidden data, or let a virus in to wreak havoc. There are precautions you can take depending on budgets and how your data is distributed.

\subsection{Case Analysis on How Employee Sabotage Affect Organizational Productivity}

Case analysis is an explanations of events designed to show how employee sabotage affect the productivity of an organization. These explanations provide the individual or his/her audience with a motive for the act committed. For self-serving reasons, the use of explanations could provide the potential saboteur with a framework for presenting his/her actions as seemingly less socially undesirable, and perhaps, legitimate. For example, a saboteur might attempt to excuse his/her actions by noting that "it was an accident" or he/she might justify his/her actions by noting that the victim of his/her act had hurt others in a similar (or worse) fashion before. Such accounting may help to relieve the possible effects of guilt and help to maintain the saboteur's self-respect by providing seemingly proper reasons for his/her activity.

Of critical importance, however, is whether these accounts will effectively mitigate the saboteur's responsibility for the action, thereby freeing the saboteur to continue his/her work life without pangs of conscience, or legal sanctions. It seems, however, that some individuals will accept many motives for a particular act like sabotage, while others will not. For example, some individuals may accept retaliation for a company wrong as the only reason for sabotage, although others may include the protection of job interests, the benefit or the "fun" involved in sabotage as justifiable reasons too. Essentially, it may be proposed that there will be individual differences in the number and type of accounts that particular persons will accept as justifiable reasons for sabotage. 
Another case analysis of how employee sabotage affect organizational productivity is presented as; inasmuch as sabotage is directed at injuring an organization, we decided to pursue our study of sabotage as a particular form of aggression. It is hypothesized that sabotage could be better understood by extrapolating and applying the extensive literature on aggression and self-presentation. Self-presentation theory (Schlenker, 2013) views individuals (workers) as motivated to maintain an identity both for themselves and an audience (fellow workers and management). Regarding aggression, Schlenker (2013) notes that a possible objective for violence might be to display a public image that is in the best interests of the aggressor, for to show an opponent during a conflict that one is tough, irrational, and capable to inflict severe harm. Similarly, the act of sabotage may stem from a management-subordinate conflict in which management insults or maligns an employee or group of employees. The insult (or other offense) would seem to make the saboteur look weak, incompetent, and cowardly. A successful counterattack is one effective way of nullifying the imputed negative identity by showing one's strength, competence, and courage (Felson and Glantz, 2016).

\section{Methodology}

This study used a survey design which enabled the researcher describe the nature of the population and determine the nature of relationships between variables of the study. The study area was Calabar Metropolis where First Bank of Nigeria Plc is located.

The population of the study consisted of the staff of First Bank of Nigeria Plc from selected branches such as; Marian branch - 31, Mayne Avenue branch - 20, Calabar road branch - 42, Mbukpa branch - 23. This makes a total of 116 employees. This study used simple random sampling technique. This allowed selection of a sample without bias. In determining the sample size for the study, the Taro Yamane (1967) formula was used. This formula was used because the population of the study is known, thus the sample size must be ascertained.

$$
\mathrm{n}=\frac{\mathrm{N}}{\mathrm{I}+\mathrm{N}(\mathrm{e})^{2}}
$$

Where:

$\mathrm{n}=$ Sample size

$\mathrm{N}=$ Finite population

$\mathrm{E}=$ Unit of tolerable error $(00.5)$

$\mathrm{I}=$ Constant

The formula applied for each of the companies selected.

$$
\text { Substituting } \mathrm{N}=116=\frac{116}{1+116(0.05)^{2}}=\frac{116}{1+0.29}=\frac{116}{1.29}=50
$$

Thus, the sample population was 50 respondents.

Data for the study were collected from both primary and secondary sources. The questionnaire was used in collecting primary data from respondents, while secondary data were collected through the review of relevant literature from the textbooks, journals and internet materials. The research instruments for the study were; questionnaire. The questionnaire on how employee sabotage affects organizational output was designed and deployed to measure the effect of variables of sabotage on organizational output. The instrument will adopt the Likert scale which ranged from strongly agree (SA), agreed (A), undecided (U) disagreed (D) to strongly disagreed (SD).

\section{Data Analysis and Findings}

Table 1. Sabotage in the organization are caused as a result of group identity and poor compensation

\begin{tabular}{lll}
\hline Option & Frequency & Percentage \\
\hline SA & 12 & 24 \\
A & 13 & 26 \\
U & 10 & 20 \\
D & 8 & 16 \\
SD & 7 & 14 \\
Total & $\mathbf{5 0}$ & $\mathbf{1 0 0}$ \\
\hline
\end{tabular}

Source: Fieldwork, 2019. 
Table 1 reveals that 12 respondents representing 24 percent indicate 'strongly agree' to the question, 13 respondents representing 26 percent indicate 'agree', 10 respondents representing 20 percent indicate 'undecided', 8 respondents representing 16 percent indicate 'disagree' and 7 respondents representing 14 percent indicate 'strongly disagree' to the question.

Table 2. Damage of organizational property by employees destroys the reputation and image of the organization

\begin{tabular}{lll}
\hline Option & Frequency & Percentage \\
\hline SA & 20 & 40 \\
A & 15 & 30 \\
U & 5 & 10 \\
D & 4 & 8 \\
SD & 6 & 12 \\
Total & $\mathbf{5 0}$ & $\mathbf{1 0 0}$ \\
\hline
\end{tabular}

Source: Fieldwork, 2019.

Table 2 shows that 20 respondents representing 40 percent indicate 'strongly agree' to the question, 15 respondents representing 30 percent indicate 'agree', five respondents representing 10 percent indicate 'moderate', 4 respondents representing 8 percent indicate 'disagree' and 6 respondents representing 12 percent indicate 'strongly disagree' to the question.

Table 3. Employees' insubordination thwarts the achievement of team work accomplishment and organizational effectiveness

\begin{tabular}{lll}
\hline Option & Frequency & Percentage \\
\hline SA & 17 & 34 \\
A & 15 & 30 \\
U & 6 & 12 \\
D & 6 & 12 \\
SD & 6 & 12 \\
Total & $\mathbf{5 0}$ & $\mathbf{1 0 0}$ \\
\hline
\end{tabular}

Source: Fieldwork, 2019.

Table 3 reveals that 17 respondents representing 34 percent indicate 'strongly agree' to the question, 15 respondents representing 30 percent indicate 'agree', 6 respondents representing 12 percent indicate 'undecided', 'disagree' and 'strongly disagree' to the question.

Table 4. Employee sabotage reduce security strength of the organization

\begin{tabular}{lll}
\hline Option & Frequency & Percentage \\
\hline SA & 20 & 40 \\
A & 15 & 30 \\
U & 5 & 10 \\
D & 4 & 8 \\
SD & 6 & 12 \\
Total & $\mathbf{5 0}$ & $\mathbf{1 0 0}$ \\
\hline
\end{tabular}

Source: Fieldwork, 2019. 
Table 4 shows that 20 respondents representing 40 percent indicate 'strongly agree' to the question, 15 respondents representing 30 percent indicate 'agree', 5 respondents representing 10 percent indicate 'undecided', 4 respondents representing 8 percent indicate 'disagree' and 6 respondents representing 12 percent indicate 'strongly disagree' to the question.

Table 5. Sabotage by employee leads to waste of resources in the organization

\begin{tabular}{lll}
\hline Option & Frequency & Percentage \\
\hline SA & 17 & 34 \\
\hline A & 15 & 30 \\
\hline U & 6 & 12 \\
\hline D & 6 & 12 \\
\hline SD & 6 & 12 \\
\hline Total & $\mathbf{5 0}$ & $\mathbf{1 0 0}$ \\
\hline
\end{tabular}

Source: Fieldwork, 2019.

Table 5 reveals that 17 respondents representing 34 percent indicate 'strongly agree' to the question, 15 respondents representing 30 percent indicate 'agree', 6 respondents representing 12 percent indicate 'undecided', 'disagree' and 'strongly disagree' to the question.

Based on the analysis, it was revealed that:

i) Employee sabotage is caused as a result of group identity and poor remuneration and compensation given to employees.

ii) Damage of organization property by employees destroys the image and reputation of the organization.

iii) Employee insubordination thwarts the achievement of team work accomplishment and organizational effectiveness.

iv) Employee sabotage reduce the security strength of the organization, thus expose the organization to competitive thread.

v) Sabotage by employee leads waste of organizational resources, and thus low organizational output.

\section{Conclusion}

Based on the findings, it was concluded that employee sabotage is caused as a result of group identity and poor remuneration and compensation given to employees. It was also concluded that sabotage at workplace by employee through damaging of property destroys the image and reputation of the organization. It was moreso concluded that employee sabotage through insubordination thwart the achievement of team work accomplishment and organizational effectiveness. Employee sabotage was concluded to reduce the security strength of the organization, thus expose the organization to competitive thread. Lastly, sabotage by employee leads to waste of resources in the organization and thus low organizational output.

\section{Recommendations}

Based on the findings, the following recommendations were made:

1) Organizations should conduct employees' background checks to know the type of employee that are hired. This can reveal a criminal record, suspicious references and lies on resumes.

2) Organization should adequately remunerate and motivate their employees so as to prevent sabotage activities.

3) Organizations should improve the security network in the workplace premises.

4) Management of organization should keep private conversations private to avoid leak of vital official information.

5) Organizations should reinforce codes of conduct which will add weight to disciplinary response (court claim) to regulate employees' behaviours. 


\section{References}

Adams, D. (2015). Predictably irrational: The hidden forces that shape our decisions. New York: Harper Collins.

Amegashie, J. (2013). Productive versus destructive efforts in contests. European Journal of Political Economy, 28(1), 461-468. https://doi.org/10.1016/j.ejpoleco.2012.05.005

Analoni, O. (2015). Sabotage in contests: A survey. Public Choice, 164, 135-155. https://doi.org/10.1007/s11127-015-0264-9

Analoui, F. (2015). Workplace sabotage: Its styles, motives and management. Journal of Management Development, 14, 48-65. https://doi.org/10.1108/02621719510097361

Berger, M. (2013). Sabotage in the workplace: The role of organizational injustice. Organizational Behavior and Human Decision Processes, 89(1), 947-965. https://doi.org/10.1016/S0749-5978(02)00037-7

Charness, J. (2014). Progress in organizational justice: Tunneling through the maze. International Review of Industrial and Organizational Psychology, 3(3), 45-68.

Chen, R. J. (1987). The predicament of injustice: The management of moral outrage. Journal of Organizational Behavior, 4(2), 56-67.

Colbert, A., Mount, M., Witt, L., Harter, J., \& Barrick, M. (2004). Interactive effects of personality and perceptions of the work situation on workplace deviance. Journal of Applied Psychology, 89(4), 599-609. https://doi.org/10.1037/0021-9010.89.4.599

Colquitt, L. (2011). Procedural and distributive justice are more similar than you think: A monistic perspective and a research agenda. Advances in Organization Justice. Staford: Stanford University Press.

Crino, D. (2014). Inclusion of other in the self-scale and the structure of interpersonal closeness. Journal of Personality and Social Psychology, 63(1), 596-612. https://doi.org/10.1037//0022-3514.63.4.596

Cropanzano, B., \& Ambrose, E. (2011). The effects of monetary incentives on effort and task performance: Theories, evidence, and a framework for research. Accounting, Organizations and Society, 27, 303-345. https://doi.org/10.1016/S0361-3682(01)00052-6

Cropanzano, B., \& Greenberg, D. (2017). Management and education of the risk of insider threat: System dynamics modeling of computer system sabotage. Journal of Business Management, 3(1), 34-54.

Felson, R., \& Glantz, B. (2016). When are victims unlikely to cooperate with police? Aggressive Behavior, 42, 97-108. https://doi.org/10.1002/ab.21626

Fisher, A., \& Baron, F. (2012). Social identity and sabotage in the organization. The Academy of Management Review, 14, 20-39. https://doi.org/10.5465/amr.1989.4278999

Flasherty, T., \& Moss, A. (2017). Sabotage in the workplace: The role of organizational injustice. Organizational Behavior and Human Decision Processes, 89, 947-965. https://doi.org/10.1016/S0749-5978(02)00037-7

Garcia, D. (2013). Employee sabotage: A random or preventable phenomenon?. Journal of Managerial Issues, 6, 311-330.

Greenberg, A. (2010). The effect of employee sabotage on management performance. Journal of Management, 2(2), 34-45.

Hannan, K. (2011). The big five personality dimensions and job performance: A meta-analysis. Personnel Psychology, 44(1), 1-26. https://doi.org/10.1111/j.1744-6570.1991.tb00688.x

Harbring S. (2014). Work attitude measures of trust, organizational commitment and personal need non-fulfillment. Journal of Occupational Psychology, 53, 39-52. https://doi.org/10.1111/j.2044-8325.1980.tb00005.X

Harbring, S., \& Irlenbusch, F. (2011). Interactional justice: Communication criteria of management practice. Journal of Management Studies, 4(1), 56-78.

Konrad, E. (2010). The role of justice in organizations: A metaanalysis. Organizational Behavior and Human Decision Processes, 86(2), 278-321. https://doi.org/10.1006/obhd.2001.2958

Lazear, P. (2017). Sabotage in promotion tournaments. Journal of Law, Economics, \& Organization, 19(1), 119-140. https://doi.org/10.1093/jleo/19.1.119 
Robinson, J., \& Bennett, A. (2015). On the dimensionality of organizational justice: A construct validation of a measure. Journal of Applied Psychology, 86(3), 386-400. https://doi.org/10.1037//0021-9010.86.3.386

Schlenker, B. (2013). Impression Management. Monterey, CA: Brooks/Cole

Skalicki, N., \& Folger, T. (2017). Tournaments, sabotage and office politics: Evidence from a real effort experiment. American Economic Review, 100(1), 504-517. https://doi.org/10.1257/aer.100.1.504

Umana, E. \& Okafor, L. (2019). The menace of groupthink on organizational performance. EPRA International Journal of Economic and Business Review, 7(4).

\section{Appendix: Questionnaire}

Department of Business Management

Faculty of Management Science

Ebonyi State University, Abakaliki

A Research Work on How Employee Sabotage Affect Organizational Output in First Bank Plc, Calabar

Dear Respondents,

I undertake this research work to determine how employee/management sabotage affects organizational output. This questionnaire is issued for the purpose of obtaining response (data) for research on the above topic. The researcher hereby solicits your honest response. All responses will be treated with utmost anonymity. The respondents, therefore, is at no risk in giving honest response to all (any) items on the questionnaire. Thanks for your cooperation.

Yours faithfully,

Etebong Umana (Researcher)

\section{Section A: Personal Data}

Sex: male \{\} female \{\}

Age: 18-29yrs \{ \} 30-39yrs \{ \} 40-49yrs \{ \} 50-59yrs \{ \} 60yrs and above \{ \}

Marital Status: single \{ \} married \{\} separated \{\} divorced \{ \} widow/widower \{\}

Highest Educational Status: WASC/SSCE \{ \} ND/NCE/OND \{ \} HND/B.SC \{ \} Ph.D \{ \}

Working Experience: 1-15yrs \{ \} 15-25yrs \{ \} 25-35yrs \{ \}

\section{Section B. Data on Researcher Variables}

KEYS: STRONGLY AGREE (SA), AGREE (A), UNDECIDED (U), DISAGREE (D) and STRONGLY DISAGREE (SD). Below is a list of items, for each, tick as appropriate.

\begin{tabular}{|c|c|c|c|c|c|c|}
\hline $\mathbf{S} / \mathbf{N}$ & STATEMENT & SA & $\mathbf{A}$ & $\mathbf{U}$ & D & SD \\
\hline 1 & $\begin{array}{l}\text { Employee sabotage are caused as a result of group identity and } \\
\text { poor remuneration and compensation given to employees }\end{array}$ & & & & & \\
\hline 2 & $\begin{array}{l}\text { Damage of organization property by employees destroys the image } \\
\text { and reputation of the organization }\end{array}$ & & & & & \\
\hline 3 & $\begin{array}{l}\text { Employee insubordination thwart the achievement of team work } \\
\text { accomplishment and organizational effectiveness }\end{array}$ & & & & & \\
\hline 4 & Employee sabotage reduce the security strength of the organization & & & & & \\
\hline
\end{tabular}

